Archives de sciences sociales des religions

136 | octobre - décembre 2006

Les Archives... cinquante ans après

\title{
Revue internationale d'éducation, Dossier école et religion
}

Sèvres, no 36, juillet 2004, 190 p.

Céline Béraud

\section{(2) OpenEdition}

\section{Journals}

Édition électronique

URL : http://journals.openedition.org/assr/4034

DOI : $10.4000 /$ assr.4034

ISSN : 1777-5825

\section{Éditeur}

Éditions de l'EHESS

Édition imprimée

Date de publication : 1 décembre 2006

Pagination : 115-283

ISBN : 2-7132-2124-2

ISSN : 0335-5985

\section{Référence électronique}

Céline Béraud, «Revue internationale d'éducation, Dossier école et religion », Archives de sciences sociales des religions [En ligne], 136 | octobre - décembre 2006, document 136-93, mis en ligne le 14 février 2007, consulté le 21 septembre 2020. URL : http://journals.openedition.org/assr/4034 ; DOI https://doi.org/10.4000/assr.4034

Ce document a été généré automatiquement le 21 septembre 2020

(C) Archives de sciences sociales des religions 


\section{Revue internationale d'éducation, Dossier école et religion}

Sèvres, no 36, juillet 2004, 190 p.

\section{Céline Béraud}

1 Dans ce numéro de 2004 d'une revue dépendant du Centre international d'études pédagogiques sont regroupées différentes contributions sur la place des religions à l'école dans différents pays européens et méditerranéens. Le dossier est introduit par Dominique Borne alors Doyen de l'Inspection générale. Y sont développées non seulement la question des signes religieux (thématique qui agitait alors l'espace scolaire français), celle du culte, mais surtout celle de l'enseignement des faits religieux (le statut des personnels qui le prennent en charge, les modalités d'établissement des programmes, les missions qui lui sont assignées). Comme dans Des maîtres et des dieux (Jean Paul Willaime, dir., en collaboration avec Séverine Mathieu, Belin, 2005), l'un des objectifs réside dans la volonté de mise en perspective du cas français et de ses spécificités concernant les rapports entre école et religion.

2 Les débats allemands ( $\mathrm{P}$. Schreiner) et britanniques (R. Jackson) précèdent la retranscription de la table ronde sur la France qui réunissait des universitaires (J.-P. Willaime, A. Legrand), des hauts fonctionnaires de l'Éducation nationale (D. Borne, P. Le Guillou, M. Sherringham) ainsi qu'un représentant de l'enseignement catholique (A. Blandin). L'évocation de l'orthodoxie dans l'espace scolaire grec (L. MolokotosLiederman) constitue le dernier cas issu de l'Union européenne. L'originalité du dossier réside dans son ouverture à d'autres aires culturelles marquées par le pluralisme religieux et un plus ou moins grand sens de la convivialité entre les cultes: A. Messara décrit la situation libanaise marquée par une querelle des manuels; D. Charbit et M. Darmoni s'intéressent au cas israëlien. Deux autres contributions traitent de pays du bassin méditerranéen confrontés au développement d'un islam radical : le Maroc (M. El Ayadi) et la Turquie (D. Duman). Enfin se trouvent présentées les formes de réintroduction d'un enseignement à propos des religions dans la Russie postsoviétique. 
3 Les différents articles, clairs et synthétiques, constituent des outils accessibles sur des questions pourtant fort complexes. On peut cependant regretter l'inégale qualité de traduction des textes rédigés en langues étrangères. En fin de dossier, un point synthétique est proposé par pays (Belgique, Danemark, Égypte, Espagne, États-Unis, Pologne) sur trois thèmes: les rapports État/religion, les structures éducatives et l'enseignement religieux. Une bibliographie est également proposée mais la partie concernant la laïcité est déjà partiellement obsolète du fait de l'abondante production éditoriale sur ce thème à l'occasion de centenaire de la loi de 1905. 